\title{
Outcome of resuscitation following unexpected apparent stillbirth
}

\author{
D M Casalaz, N Marlow, B D Speidel
}

\begin{abstract}
There are few data to inform a decision to resuscitate babies who are unexpectedly stillborn. The outcome for 42 successfully resuscitated stillborn children, of whom $62 \%$ survived to be discharged home, is reported. Of the survivors, a poor outcome with severe disability was found in $23 \%$ (including one postneonatal death), equivocal outcome was found in $15 \%$ (two mild hypertonia; two with mild hemiplegia and no associated other disability) and $62 \%$ were free of any impairment at follow up 20 months to 8 years later. In $39(93 \%)$ fetal problems had been identified and the resuscitation team was present at delivery. Poor outcome was associated with late return of heart beat, delayed respirations, neonatal acidaemia and early onset of seizures. Of the unexpected apparent stillbirths successfully resuscitated, $52 \%$ died or survived severely disabled, $10 \%$ had an equivocal outcome, but $36 \%$ survived apparently intact. Therefore, vigorous resuscitation is clearly indicated in these circumstances.
\end{abstract}

(Arch Dis Child Fetal Neonatal Ed 1998;78:F112-F115)

Keywords: stillbirths; resuscitation; disability

One of the most difficult scenarios encountered in the delivery room is the unexpected birth of a baby who has no audible heart beat. There are few data that can inform attendants on how to proceed. The most widely quoted study is that of Scott and colleagues, ${ }^{1}$ who reported the outcome for babies born with "low" Apgar scores at 1 minute $(<3)$, a group which included 15 babies with no heart beat $(1$ minute Apgar score of 0 ), of whom eight (53\%) survived. Longer term outcomes were not, however, described for that particular subgroup. In a more recent study Jain and colleagues, $^{2}$ reported the outcome for 62 successfully resuscitated stillbirths of whom 36 $(58 \%)$ survived to discharge. Of the 33 long term survivors, 23 were assessed for disability; this was present in $70 \%$, suggesting a bleak outlook for this group.

In view of the paucity of data in this area, we reviewed the outcome for all babies born with no audible heart beat at 1 minute in two Bristol maternity units over 100 months, to evaluate the prevalence of intact survival in this group and to identify predictors which might be of value to the clinical team.

\section{Methods}

We identified all babies born with an Apgar score of zero at 1 minute and who were 24 or more weeks of gestation, during the period 1 October 1986 to 31 December 1994, at the two maternity units in Bristol at St Michael's and Southmead Hospitals. The population was identified from delivery room and neonatal unit records and cross referenced against the annual perinatal reports of both units. Cases were confirmed by examining the maternal and neonatal clinical notes. Data were abstracted from the maternal obstetric records and from paediatric case notes. Where the child was no longer under follow up from the hospital or community child health services, family doctors were contacted and the primary care team provided information as to current health status. Information was available on the health status of all survivors at between 1 year 8 months and 8 years of age.

Perinatal data were abstracted from the clinical notes and encoded for computer analysis.

\section{Results}

Over the period of study there were 94511 deliveries at the two hospitals. Four hundred and nine stillbirths at 24 or more weeks of gestation were recorded; intrauterine death was anticipated for 406 deliveries and no resuscitation attempted. For three unexpected stillbirths, resuscitation was attempted but failed, giving a stillbirth rate of 4.3 per 1000 births $\geqslant 24$ weeks. The change in definition of stillbirth in October 1992 (from 28 to 24 weeks of gestation) resulted in a published rate of 4.0 per 1000 births up to December 1992 and 5.6 per 1000 births for 1993-4.

Forty five babies were born in unexpectedly poor condition and were allocated an Apgar score of zero at 1 minute. Of these, 42 (93\%) were "successfully" resuscitated and admitted to the neonatal intensive care unit (table 1). The "unanticipated" stillbirth rate was therefore 0.5 per 1000 births $\geqslant 24$ weeks of gestation. Of these forty two, $26(62 \%)$ were born at term and $16(38 \%)$ preterm (24-36 weeks).

Presentation was known for all 42 babies, 33 were vertex, seven breech, one shoulder and one compound (hand). Delivery was by caesarean section in $26(62 \%)$ cases ( 21 of 33 vertex, four of seven breech presentations). Instrumental delivery occurred in four. Shoulder dystocia occurred in four. Only four were born by spontaneous vertex vaginal delivery. In 1993 and 1994,13 of the 15 babies were born by caesarean section. 
Adverse perinatal events were noted in 39 children (93\%). Acute events occurred in 37 $(88 \%)$, and included poor fetal heart rate trace (24), antepartum haemorrhage (10), and malpresentation (9), shoulder dystocia (4), cord prolapse (2), true knot in umbilical cord (1) and uterine rupture following trial of scar (1). Less acute events were present in $14(33 \%)$ : pre-eclampsia/maternal hypertension (7), known fetal growth retardation (4), twin to twin transfusion/twin pregnancy (3), and prolonged membrane rupture (2). One patient, with a breech presentation, refused antenatal care and discharged herself despite being in labour. The after-coming head was stuck on the cervix when she represented.

Doctors with training in neonatal resuscitation were present at the birth of all 39 children and allocated the initial Apgar score. In only three cases $(7 \%)$ were there no identified antenatal risk factors with no trained advanced resuscitator initially present.

Only $23(55 \%)$ babies were appropriately grown for their gestation; 11 had birthweights below the 10th centile for gestation $(26 \%$ term and $27 \%$ preterm babies) and eight (19\%) had birthweights above the 90th centile, including the four babies with shoulder dystocia.

Twenty six of the 42 babies admitted to the neonatal units at the two hospitals (62\%) survived to be discharged home; 16 (38\%) died in the neonatal period. Survival was similar for term and preterm babies: 18 (67\%) term babies compared with eight (50\%) preterms). Four deaths occurred in the first 24 hours, three during the second day and the remainder before the end of the first week. Early arterial $\mathrm{pH}$ was recorded in $32(80 \%)$ babies. For those who died or survived with a severe disability, median $\mathrm{pH}$ was 6.97 (range: 6.7-7.33) and 6.97 (6.89-7.23), respectively, compared with 7.15 (6.7-7.39) in normal survivors. For the two children with $\mathrm{pH}$ records and mild/ moderate disability, the values were 7.18 and 7.21 , respectively. Despite the difference in median values there was much overlap between the groups (fig 1). The worst stage of encephalopathy was not reliably recorded before 1990 . Seizures were therefore taken as a surrogate of encephalopathy and occurred in 21 children. Of three deaths without seizures, one was an extremely preterm infant who died in the first week of respiratory disease with associated intraventricular haemorrhages, the remaining two died at 1 and 4 hours of age, respectively, with other signs of severe encephalopathy. Seizures occurs in five of 10 disabled children (one mild/moderate) and two of 16 normal survivors.

Table 1 Clinical details of 42 children resuscitated after inital stillbirth and admitted for neonatal intensive care

\begin{tabular}{|c|c|c|c|c|c|c|c|c|c|c|}
\hline \multirow[b]{2}{*}{ Case No } & \multirow[b]{2}{*}{$\operatorname{Sex}$} & \multirow[b]{2}{*}{ Gestation } & \multirow[b]{2}{*}{ Birthweight } & \multicolumn{4}{|c|}{ Apgar scores at (mins): } & \multirow[b]{2}{*}{ Delivery } & \multirow[b]{2}{*}{ pH in first 2 hours } & \multirow[b]{2}{*}{ Outcome } \\
\hline & & & & 1 & 5 & 10 & 20 & & & \\
\hline 1 & M & 39 & 2510 & 0 & 3 & 6 & & $\mathrm{CS}$ & 6.70 & Normal \\
\hline 2 & $\mathrm{~F}$ & 33 & 1830 & 0 & 5 & 6 & & $\mathrm{~F}$ & 7.23 & Quadriplegia \\
\hline 3 & M & 27 & 830 & 0 & 1 & 2 & 6 & B & 7.20 & Died day 3 \\
\hline 4 & M & 43 & 3790 & 0 & 3 & 3 & & CS & 6.98 & Quadriplegia* \\
\hline 5 & $\mathrm{~F}$ & 36 & 2460 & 0 & 0 & 0 & 4 & $\mathrm{CS}$ & & Died $>3 d$ \\
\hline 6 & $\mathrm{~F}$ & 38 & 2970 & 0 & 0 & 2 & 4 & CS & 6.90 & Died $>3 d$ \\
\hline 7 & $\mathrm{~F}$ & 40 & 2850 & 0 & 6 & 9 & 10 & $\mathrm{CS}$ & & Normal \\
\hline 8 & M & 39 & 2470 & 0 & 2 & 9 & 10 & $\mathrm{CS}$ & & Normal \\
\hline 9 & $\mathrm{~F}$ & 31 & 1710 & 0 & 0 & 1 & 4 & CS & 6.97 & Died $>3 d$ \\
\hline 10 & M & 40 & 4170 & 0 & 5 & 8 & & $\mathrm{~V}$ & 7.18 & Normal \\
\hline 11 & $\mathrm{~F}$ & 37 & 4970 & 0 & 0 & 0 & 0 & $\mathrm{~F}$ & 6.89 & Quadriplegia $†$ \\
\hline 12 & $M$ & 24 & 800 & 0 & 4 & 4 & 6 & V & 7.37 & Normal \\
\hline 13 & $M$ & 40 & 3240 & 0 & 4 & 6 & & CS & 6.99 & Quadriplegia \\
\hline 14 & $M$ & 37 & 4500 & 0 & 8 & 10 & & $\mathrm{~V}$ & 7.39 & Normal \\
\hline 15 & $\mathrm{~F}$ & 42 & 5020 & 0 & 6 & 9 & & $\mathrm{~V}$ & & Normal \\
\hline 16 & M & 33 & 2450 & 0 & 0 & 3 & & CS & & Died $>3 d$ \\
\hline 17 & $M$ & 39 & 3680 & 0 & 3 & 4 & 9 & $\mathrm{~V}$ & 7.30 & Normal \\
\hline 18 & $\mathrm{~F}$ & 40 & 3795 & 0 & 5 & 7 & & $\mathrm{~V}$ & & Normal \\
\hline 19 & $\mathrm{~F}$ & 32 & 865 & 0 & 1 & 3 & & V & & Normal \\
\hline 20 & $\mathrm{~F}$ & 40 & 3360 & 0 & 6 & 10 & & CS & 7.12 & Normal \\
\hline 21 & $\mathrm{~F}$ & 40 & 4335 & 0 & 2 & 3 & & Vent & 7.08 & Died $>3 d$ \\
\hline 22 & $\mathrm{~F}$ & 39 & 3325 & 0 & 4 & 5 & 6 & $\mathrm{CS}$ & 7.05 & Normal \\
\hline 23 & M & 41 & 3200 & 0 & 0 & 0 & 1 & V & 6.82 & Died $>3 d$ \\
\hline 24 & M & 35 & 3050 & 0 & 4 & 4 & 7 & $\mathrm{~F}$ & 7.33 & Died $>3 d$ \\
\hline 25 & $\mathrm{~F}$ & 25 & 1005 & 0 & 6 & 9 & & B & & Normal \\
\hline 26 & $\mathrm{~F}$ & 40 & 3000 & 0 & 4 & 4 & & $\mathrm{CS}$ & 7.10 & Died $>3 d$ \\
\hline 27 & $\mathrm{~F}$ & 39 & 3325 & 0 & 4 & 5 & 6 & $\mathrm{CS}$ & 7.00 & Normal \\
\hline 28 & $\mathrm{~F}$ & 29 & 1120 & 0 & 1 & 5 & & CS & 7.18 & Mild hypertonia \\
\hline 29 & $\mathrm{~F}$ & 37 & 2400 & 0 & 1 & 4 & 5 & $\mathrm{CS}$ & 7.21 & Mild hemiplegia \\
\hline 30 & M & 42 & 4060 & 0 & 0 & 0 & 2 & $\mathrm{CS}$ & & Died at $1 \mathrm{~h}$ \\
\hline 31 & $\mathrm{~F}$ & 28 & 865 & 0 & 8 & 9 & & CS & & Mild hemiplegia \\
\hline 32 & $\mathrm{~F}$ & 40 & 4580 & 0 & 1 & 4 & & $\mathrm{~V}$ & 6.96 & Quadriplegia \\
\hline 33 & $M$ & 37 & 3475 & 0 & 4 & 7 & & CS & 7.08 & Normal \\
\hline 34 & $\mathrm{~F}$ & 41 & 3180 & 0 & 0 & 3 & & CS & 7.08 & Died at $19 \mathrm{~h}$ \\
\hline 35 & $\mathrm{~F}$ & 32 & 1385 & 0 & 0 & 2 & & CS & 6.70 & Died at $4 \mathrm{~h}$ \\
\hline 36 & $\mathrm{~F}$ & 37 & 3000 & 0 & 4 & 7 & & CS & 6.82 & Died $11 \mathrm{~h}$ \\
\hline 37 & $\mathrm{~F}$ & 42 & 3070 & 0 & 2 & 4 & 5 & $\mathrm{CS}$ & 6.77 & Died day 2 \\
\hline 38 & $\mathrm{~F}$ & 27 & 950 & 0 & 4 & 6 & & CS & & Mild hypertonia \\
\hline 39 & $\mathrm{~F}$ & 33 & 1960 & 0 & 1 & 4 & & CS & 6.84 & Died day 2 \\
\hline 40 & $\mathrm{~F}$ & 36 & 2600 & 0 & 3 & 3 & 3 & B & 7.01 & Died day 2 \\
\hline 41 & $\mathrm{~F}$ & 36 & 2700 & 0 & 7 & 9 & & $\mathrm{CS}$ & 7.23 & Normal \\
\hline 42 & M & 39 & 2940 & 0 & 0 & 4 & & CS & 6.94 & Quadriplegia \\
\hline
\end{tabular}

V: vertex vaginal; B: vaginal breech; F: forceps; Vent: Ventouse; CS: caesarean section.

$\star$ Died at 4 years of age.

t Heart rate noted at 22 minutes. 


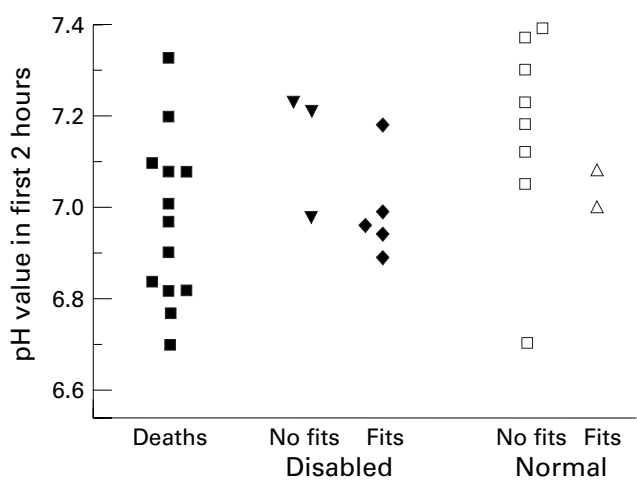

Figure 1 Results of $p H$ estimations in the first two hours after birth, and outcome.

One child, who had established severe disability, died at 4 years of age. The remaining $25(60 \%)$ were alive in August 1996. Of these, $16(64 \%)$ are free of any abnormality at follow up- $12(67 \%)$ of 18 term survivors and four $(50 \%)$ of the eight preterm survivors. Two of these had transient brachial plexus injury as a result of shoulder dystocia.

Four children (16\%), aged from 20 to 36 months, have equivocal outcomes recorded at their most recent follow up: two had mild generalised hypertonicity and two mild spastic hemiplegia, but with normal progress in other areas and no developmental delay. These are classified as a mild-moderate disability group.

Six $(23 \%)$ survived the neonatal period severely disabled, with dyskinetic spastic quadriplegic cerebral palsy and global dysfunction. In three of these there was evidence of neurological impairment at discharge with persisting hypotonia and feeding difficulty, including the 4 year old child who died. Of the 26 neonatal survivors, poor outcome occurred in $23 \%$, intermediate outcome in $15 \%$, and a normal outcome in $62 \%$ among the 26 neonatal survivors.

We evaluated several clinical variables from the immediate neonatal period as predictors of poor outcome, defined as death or severe disability at follow up: presence of heart beat at 5 and 10 minutes; Apgar score at 5 and 10 minutes; time to onset of spontaneous respirations and measurements from the first blood gas sample taken after admission to the neonatal unit, occurrence and start of seizures.

Of the 10 babies (24\%) with an absent heart beat at 5 minutes, eight died in the neonatal period and the remaining two babies are severely disabled. These comprise half the deaths and one third of those with severe disability. Just over half the study group had an Apgar score of less than 4 at 5 minutes. Of these 23, 13 died, six have a disability (four severe), and four $(17 \%)$ have survived intact. Ten minutes after birth, 14 (33\%) had an Apgar score of less than 4:11 died, two have severe disability, and only one $(7 \%)$ survives without impairment.

An arterial or capillary sample for blood gas analysis was recorded within two hours of birth in $28 / 42(67 \%)$. Of 13 with a $\mathrm{pH}$ of $<7.0$, only one has survived without disability; three of six had good outcomes, with a $\mathrm{pH}$ between 7.0

\section{Key points}

- Unexpected stillbirth occurs in 0.5/1000 births over 24 weeks of gestation; most have indentifiable obstetric or perinatal antecedents

- Over $60 \%$ of these infants are successfully resuscitated; of these, over $60 \%$ have no long term disability, but one in five do

- Poor outcome of resuscitation, both long and short term, is associated with late return of heart beat/respiration, the presence of acidaemia in the first 2 hours after birth, and early onset of seizures

- Vigorous resuscitation of unexpectedly stillborn infants is clearly indicated

and 7.1, compared with six of nine children with a $\mathrm{pH}>7.1$.

Seizures were documented in a total of $21 / 42$ $(50 \%)$, with $18(42 \%)$ having seizures noted in the first 24 hours after birth. Eleven of the 18 died (10 in the neonatal period), four have severe disability, and two survive intact. Thirteen $(31 \%)$ had seizures recorded in the initial 12 hours after delivery, and of this group, 10 died (nine in the neonatal period) and three have ongoing severe disability.

Those with delayed return to normal of physiological variables - delayed restoration of heart beat and clinical condition, or with persisting severe acidosis-tend to have poor outcome, both in terms of survival and subsequent neurodevelopment. Likewise, the occurrence of seizures in the first 24 hours after birth, and in particular the first 12 hours, was associated with poor survival and developmental outcome.

\section{Discussion}

In an average sized maternity unit, with 3000 deliveries a year, a paediatrician can be expected to see a baby born unexpectedly with no audible heart beat up to twice each year. It is of critical importance that resuscitation is begun, knowing that survival without disability is common after such an event and those criteria which may inform the decision as to whether it should be abandoned or pursued vigorously.

Until recently, decision making was based on the data of Scott et al, from births between 1966 and $1971 .^{1}$ However, this study grouped babies with absent heart beat at birth with others who had Apgar scores of between 1 and 4; only 15 babies were given a 1 minute Apgar score of zero and, of these, eight survived; their subsequent neurodevelopmental status is not reported separately. Similar data were reported by Steiner and Neligan, ${ }^{3}$ and Thompson et $a l_{,}{ }^{4}$ from severely asphyxiated births between 1964 and 1974. Both neonatal survival and intensive care techniques have changed substantially since then and it seems appropriate to re-evaluate this particular risk group. More recently, there have been two reports of outcome following resuscitated stillbirth: Jain and colleagues reported 62 cases, collected 
over five years, ${ }^{2}$ in Illinois, USA, and Yeo and Tudehope reported 45 cases over 10 years $^{5}$ from Brisbane, Australia. Survival in these two series was remarkably similar at $58 \%$ and $60 \%$, respectively, and compares with $62 \%$ in our series.

The studies differ, however, in the prevalence of severe disability among survivors. Jain et al report a rate of $70 \%$ based on 23 of 36 survivors, giving a estimate of between $44 \%$ and $81 \%$ for their full population, depending on the status of their unascertained children. Yeo and Tudehope report that $35 \%$ of their ascertained population had severe disability, giving a possible range of between 30 and $45 \%$ in their full population. We achieved $100 \%$ follow up and found poor outcome (death or severe disability) less frequently than either previous study $(23 \%$; 95\% confidence intervals (CI) $10 \%$ to $44 \%$ ). Combining the outcomes for ascertained children across the three studies, 31 of 72 identified children had severe disability at follow up $(43 \% ; 95 \%$ CI $31 \%$ to $55 \%)$. This compares with rates of normal development among survivors of $100 \%,{ }^{4} 75 \%,{ }^{1}$ and $66 \%{ }^{3}$ in the three older studies, which included children with higher Apgar scores.

In this study most babies survived, and most of these had no severe disability. However, for most deliveries fetal problems had been identified before birth, delivery was therefore expedited, and the resuscitation team was able to attend $93 \%$ of the deliveries. In the other two recent publications this was not reported. This may have two advantages for our population. Firstly, it allows us to be confident about the clinical status of the child at birth and the allocation of the Apgar score, which remains the mainstay of clinical description of status at birth. Although recording the Apgar score remains problematical, ${ }^{6}$ in the case of a zero score at 1 minute it may be argued that consistency is more likely. Secondly, the identification of fetal problems ensured that poor fetal condition was anticipated and resuscitation started immediately. There was, therefore, minimal postnatal hypoxia to contribute to the asphyxial injury.

Indicators of poor outcome were as anticipated and include a 5 and 10 minute Apgar score of 3 or less, the presence of a measured $\mathrm{pH}$ in the first 2 hours of less than 7.0, and the absence of heart beat at 5 minutes. Conventional teaching suggests that if the heart beat has not returned after 10 minutes of appropriate resuscitation, resuscitative efforts should be abandoned. None of this small group in our study survived without severe disability. The poor outcome associated with severe initial acidosis in our study contrasts with one other study in which it was suggested that babies who respond to severe asphyxia with an acidosis, as measured by cord blood sampling, may fare better than their counterparts who do not. ${ }^{7}$ However, not all children had $\mathrm{pH}$ values recorded soon after admission and further extrapolation from our data is unwise.

Babies with evidence of severe neurological injury, as manifest by early seizures, are unlikely to survive, and survivors are likely to have severe long term neurodevelopmental consequences. This correlates with the data of Yeo and Tudehope, who found that features of hypoxic-ischaemic encephalopathy of Sarnat stages 2 or 3, were associated with a high probability of mortality and morbidity in survivors. ${ }^{5}$ Recent data indicate that early EEG abnormalities may equally predict poor outcome, ${ }^{8}$ lending support to our observation that babies with early seizures are at particular risk.

The consistency of information in the three recent studies indicates that these data could be used to inform decision making and counsel parents as to the prognosis for successfully resuscitated, apparently stillborn infants. We consider that attempts at resuscitation for babies born with no audible heart beat are justified, as $48 \%$ of successfully resuscitated children are likely to have no severe disability at follow up.

We are grateful to Drs P Buss and R L Gueran for data collection.

1 Scott H. Outcome of very severe birth asphyxia. Arch Dis Child 1976; 51:712-6

2 Jain L, Ferre C, Vidyasagar D, et al. Cardiopulmonary resuscitation of apparently stillborn infants. F Pediatr 1991; 118:778-82.

3 Steiner H, Neligan G. Perinatal cardiac arrest: Quality of the survivors. Arch Dis Child 1975; 60:696-702.

4 Thompson A J, Searle M, Russell G. Quality of survival after severe birth asphyxia. Arch Dis Child 1977; 52:620-6.

5 Yeo C L, Tudehope D 1. Outcome of resuscitated apparently stillborn infants: A ten year review. 7 Paediatr Child Health stillborn infants:

6 Marlow N. Do we need an Apgar score? Arch Dis Child $1992 ; 67: 765-9$

7 Sykes GS, Molloy PM, Johnson P, et al. Do Apgar scores indicate perinatal asphyxia? Lancet 1982; i:494-6.

8 Van Lieshout H B, Jacobs JW, Rotteveel J J, et al. The prognostic value of the EEG in asphyxiated newborns. Acta Neurologica Scand 1995; 91:203-7. 